\title{
Exploring Glycosylation Reactions under Continuous-Flow Conditions
}

\author{
Damiano Cancogni, Luigi Lay* \\ Dipartimento di Chimica and ISTM-CNR, Università degli Studi di Milano, Via Golgi 19, 20133 Milano, Italy \\ Fax+390250314072; E-mail: luigi.lay@unimi.it \\ Received: 25.06.2014; Accepted after revision: 16.09.2014
}

\begin{abstract}
The industrial development of carbohydrate-based drugs is greatly thwarted by the typical challenges inherent in oligosaccharide synthesis. The practical advantages of continuous-flow synthesis in microreactors (high reproducibility, easy scalability, and fast reaction optimization) may offer an effective support to make carbohydrates more attractive targets for drug-discovery processes. Here we report a systematic exploration of the glycosylation reaction carried out under microfluidic conditions. Trichloroacetimidates and thioglycosides have been investigated as glycosyl donors, using both primary and secondary acceptors. Each microfluidic glycosylation has been compared with the corresponding batch reaction, in order to highlight advantages and drawbacks of microreactors technology. As a significant example of multistep continuous-flow synthesis, we also describe the preparation of a trisaccharide by means of two consecutive glycosylations performed in interconnected microreactors.
\end{abstract}

Keywords: carbohydrates, glycosylation, flow chemistry, natural products, oligosaccharides, glycosides

Beside peptides and nucleotides, carbohydrates are one of the most important biopolymers found in nature, in fact they play crucial roles as key mediators of vital molecular recognition phenomena and signal transduction. In addition, carbohydrates are involved in other different biological events such as bacterial and viral infections, inflammatory processes, and tumor growth and metastasis. ${ }^{1}$ All these characteristics make carbohydrates attractive targets for the design and development of new drugs. ${ }^{2}$ However, there are still severe limitations to the development of saccharide-based drugs using traditional carbohydrate synthesis, even though some enormously successful pharmaceutical compounds based on synthetic oligosaccharides have been approved for the market during the past decade, such as the anticoagulant fondaparinux $\left(\right.$ Arixtra $^{\mathrm{TM}}$ ) and the antiviral zanamivir (Relenza ${ }^{\mathrm{TM}}$ ).

Classical carbohydrate synthesis is a multistep process typically afflicted by laborious protecting-group manipulations, often requiring tedious work-up and time-consuming purification steps. ${ }^{3}$ In addition the glycosylation, the most important transformation in the chemical synthesis of carbohydrates, is still a challenging task. Although multitudinous approaches for the stereoselective formation of glycosidic bonds have been thoroughly explored during the last two decades, ${ }^{4}$ a general method for the preparation of different glycoconjugates has yet not

SYNLETT 2014, 25, 2873-2878

Advanced online publication: 17.10.2014

DOI: 10.1055/s-0034-1379471; Art ID: st-2014-b0544-1

(c) Georg Thieme Verlag Stuttgart · New York emerged, especially for large-scale production of oligosaccharides. As a consequence, the ideal reaction conditions (in terms of the protecting-group pattern of the condensing partners, reagents concentration, stoichiometry, temperature, and nature of the acidic promoter) have to be found, in theory, for each couple of glycosylation partners, leading to waste of time and high consumption of precious building blocks, which are valuable synthetic intermediates and they themselves require multistep synthesis. All of these drawbacks are inherent in carbohydrate synthesis and represent notable obstacles for the industrial development of carbohydrate-based pharmaceutical compounds.

Continuous-flow organic synthesis carried out in microreactors may offer an attractive solution, since the optimization of the reaction conditions and the subsequent scale-up are very fast and simple. ${ }^{5}$ Due to the small dimensions and the increased surface to volume ratio of microreactors, mass and heat transport are significantly more efficient than in the classic round-bottomed flask. As a result, the reaction conditions in a continuous-flow microsystem are homogeneous, and variables such as temperature, pressure, concentration, and residence time can be easily and very precisely controlled, improving yield, purity, and selectivity. In addition, only a small amount of starting material is required to rapidly screen multiple reaction conditions, thus reducing the waste of precious intermediates. On the other hand, the continuous running of the microreactor or the use of multiple microreactors in parallel allow for a simple scale-up of the optimized process.

Because of the many practical advantages mentioned above, the use of microfluidic reactors could speed up the saccharide drug discovery and the development process, in order to adequately exploit the broad potential envisioned for this class of molecules in pharmaceutical and medicinal field. Nonetheless, in comparison with other areas of chemistry the application of this technique to oligosaccharide synthesis is still in its infancy. In particular, relatively few examples of glycosylations in a flow microreactor system have been reported. ${ }^{5 g, 6}$ More recently, this technique has been extended to the synthesis of fluorinated glycosyl amino acids ${ }^{7}$ and the photochemical coupling of sugars via thiol-ene chemistry. ${ }^{8}$ The application of continuous-flow devices to perform the multistep synthesis of complex molecules, that can be achieved by combining multiple steps through a series of properly interconnected microreactors, represents an additional advantage of this technique. ${ }^{9}$ Such an approach would allow to circumvent the conventional and time-consuming isolation and puri- 
fication procedures usually needed for each intermediate product in traditional reaction sequences. The group of Jamison exemplified this concept with the continuousflow multistep synthesis of nucleosides. ${ }^{10}$

With the aim of gaining more insights into the potential of microreactors in oligosaccharide synthesis, here we report on a study of glycosylation reaction performed under continuous-flow conditions using different glycosyl donors and acceptors. In particular, both primary and secondary acceptors (monosaccharides 1-3, Scheme 1) have been used in this study, while thioglycosides and glycosyl trichloroacetimidates have been selected as glycosyl donors. Each glycosylation has been also carried out under traditional batch conditions, in order to compare the results both in terms of chemical yield and stereoselectivity. Finally, we describe the straightforward preparation of a trisaccharide by means of two sequential microfluidic glycosylations performed in two interconnected microreactors. ${ }^{11}$

First, one primary (glucoside 1, Scheme 1) and two secondary acceptors (compound $\mathbf{2}$ and the more sterically hindered glucoside 3, Scheme 1) were synthesized from methyl $\alpha$-D-glucopyranoside following known procedures $^{12}$ (see the Supporting Information file).

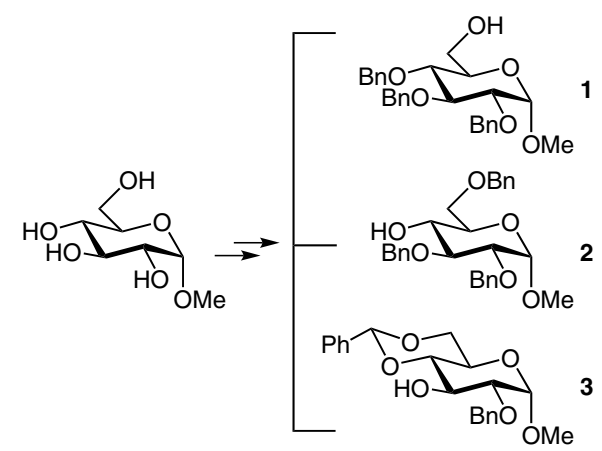

Scheme 1 Glucosyl acceptors employed in this study

Then, a panel of glycosyl donors differing for conformational rigidity and activating group at the anomeric carbon was synthesized according to literature procedures. In particular, the most popular and widespread classes of glycosyl donors, trichloroacetimidates and thioglycosides, were selected and employed in this study. Moreover, all the glycosyl donors do not have participating groups at C-2, so that a possible influence of the microfluidic conditions on the glycosylation stereoselectivity could emerge.

Glucosyl trichloroacetimidates 4 and 5 (Figure 1) were prepared as previously described..$^{13}$ Ethyl- and $p$-tolyl thioglycosides 6 and 7, and their corresponding more conformationally rigid counterparts 8 and $\mathbf{9}$ (Figure 1), were synthesized from pentaacetylglucose ${ }^{14}$ (see the Supporting Information file).

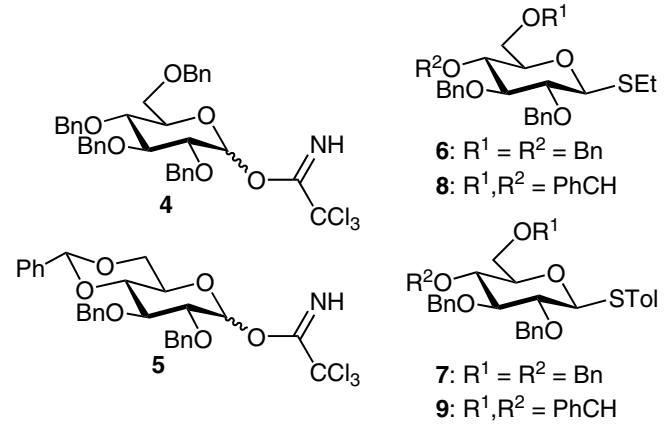

Figure 1 Glucosyl donors employed in this study

All the batch glycosylations were carried out at room temperature in dry dichloromethane under inert atmosphere and quenched by addition of triethylamine after disappearance of the glycosyl donor (5 min). Flow glycosylations were instead performed at room temperature pumping into a microreactor with an internal volume of $13 \mu \mathrm{L}$ (purchased by Micronit Microfluidics ${ }^{\mathbb{Q}}$ ) two distinct solutions in reagent grade dichloromethane, containing the glycosyl donor and acceptor (1.2:1 ratio, solution A) and the acidic promoter (0.01 M TMSOTf, solution B). In the glycosylations performed with thioglycosyl donors, solution A contained also the $N$-iodosuccinimide (NIS) required for anomeric activation. A fine tuning of the hydrodynamic pumping (using a conventional double syringe pump) allowed to adjust the flow rate, that is, the residence time in the microreactor. The device is completed by a reservoir connected to the outlet of the microreactor and containing a solution of triethylamine in dichloromethane to neutralize the promoter and quench the reaction (Figure 2). Experimental details of all batch and microfluidic glycosylations, as well as ${ }^{1} \mathrm{H}$ NMR spectra highlighting the $\alpha / \beta$ ratios, are included in the Supporting Information file.

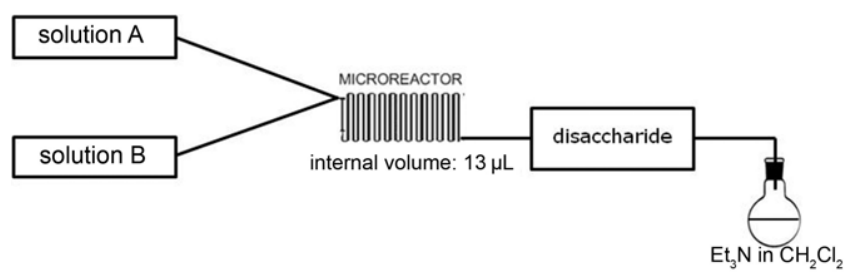

Figure 2 Representation of continuous-flow glycosylations

In the first set of experiments, the trichloroacetimidate donor $\mathbf{4}$ was reacted with acceptors 1-3 (Scheme 2). Initially, the residence time of the microfluidic reactions was set at five minutes.

Despite the use of reagent grade instead of dry solvent and room temperature, which are unusual conditions for most glycosylations, all the flow reactions afforded the corresponding disaccharides 10-12 in moderate to good isolated yields, while the stereoselectivity was comparable with that of the batch reactions (Table 1, entries 2, 7, and 10). 


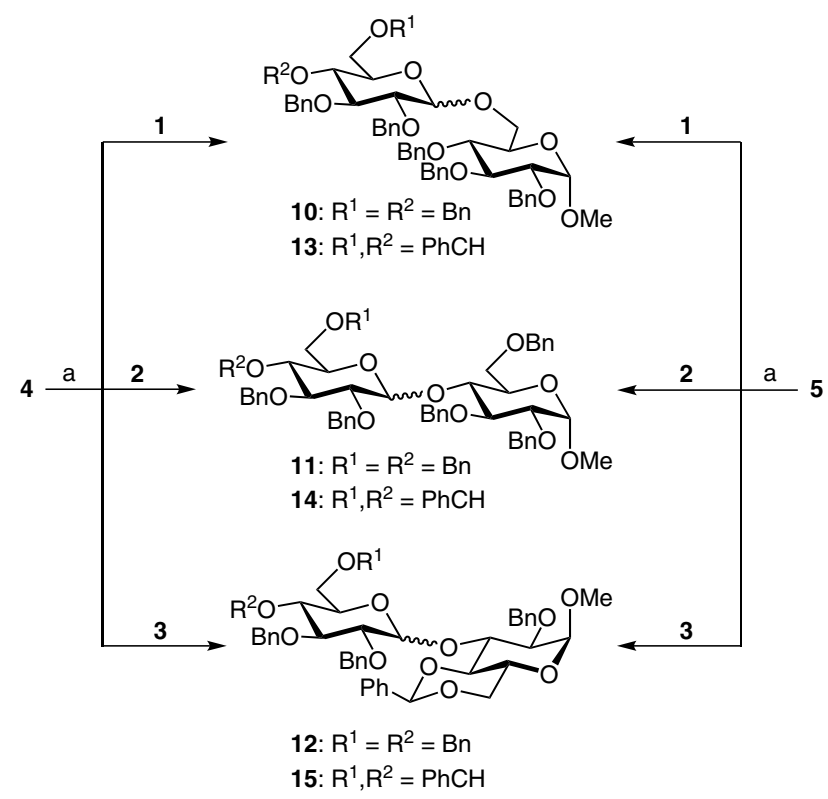

Scheme 2 Reagents and conditions: (a) TMSOTf (0.01 M), $\mathrm{CH}_{2} \mathrm{Cl}_{2}$.

Interestingly, when the reaction time of the microfluidic reactions was reduced to one minute, a significant increase of the chemical yields was observed (Table 1, compare entries $2,3,7,8$, and 10,11 ), while the $\alpha / \beta$ ratio remained almost unchanged. The most sterically hindered acceptor 3 provided exclusively the $\alpha$ disaccharide 12 under all the conditions tested (Table 1, entries 9-11). In a separate experiment, we investigated the influence of the temperature on the course of the microfluidic glycosylation of acceptor 1 with donor 4 (Table 1, entries 4 and 5). However, going from room temperature to $0{ }^{\circ} \mathrm{C}$ we observed only a slight increase of the chemical yield (and a decrease of the stereoselectivity), while at $-20^{\circ} \mathrm{C}$ the precipitation of the trichloroacetamide caused the microchannels occlusion. All the following glycosylations were therefore performed at room temperature.

Trichloroacetimidate $\mathbf{5}$ afforded very similar results to donor 4 (Scheme 2 and Table 1). The only exception was again the glycosylation of acceptor $\mathbf{3}$. This reaction showed high $\alpha$ stereoselectivity under batch conditions (15:1 $\alpha / \beta$ ratio), and reached an excellent 19:1 with 0.5 minutes residence time in the microreactor (Table 1 , entries 18 and 20, respectively). On the other hand, the reduction of the residence time to 0.5 minutes did not bring any apparent advantage with acceptors $\mathbf{1}$ and $\mathbf{2}$ (Table 1, compare entries 13,14 and 16,17). We therefore deemed that the good $\alpha$ stereoselectivity achieved only with acceptor 3 should be ascribed to matching steric effects, rather than to a specific influence of the microfluidic conditions. The residence time of one minute was then considered optimum for our system, and this value was fixed in all the subsequent experiments.

It is reasonable to assume that the reduced diffusion distances and reaction volumes, as well as the very accurate control of the reaction parameters ensured by the micro-
Table 1 Glycosylations Performed with Trichloroacetimidate Donors 4 and 5

\begin{tabular}{|c|c|c|c|c|c|c|}
\hline Entry & Donor & Acceptor & Product & $\begin{array}{l}\text { Time } \\
(\mathrm{min})\end{array}$ & $\begin{array}{l}\text { Yield } \\
(\%)^{\mathrm{c}}\end{array}$ & $\alpha / \beta^{\mathrm{d}}$ \\
\hline $1^{\mathrm{a}}$ & 4 & 1 & 10 & 5 & 66 & $2.4: 1$ \\
\hline $2^{\mathrm{b}}$ & 4 & 1 & 10 & 5 & 81 & $1.8: 1$ \\
\hline $3^{\mathrm{b}}$ & 4 & 1 & 10 & 1 & 95 & $1.6: 1$ \\
\hline $4^{b}$ & 4 & 1 & 10 & 1 & $99^{\mathrm{e}}$ & $1: 1$ \\
\hline $5^{\mathrm{b}}$ & 4 & 1 & 10 & 1 & $26^{\mathrm{fgg}}$ & $1: 1.8$ \\
\hline $6^{\mathrm{a}}$ & 4 & 2 & 11 & 5 & 28 & $1: 1.3$ \\
\hline $7^{\mathrm{b}}$ & 4 & 2 & 11 & 5 & 50 & $1.3: 1$ \\
\hline $8^{b}$ & 4 & 2 & 11 & 1 & 77 & $1.6: 1$ \\
\hline $9^{\mathrm{a}}$ & 4 & 3 & 12 & 5 & 58 & $1: 0$ \\
\hline $10^{\mathrm{b}}$ & 4 & 3 & 12 & 5 & 50 & $1: 0$ \\
\hline $11^{\mathrm{b}}$ & 4 & 3 & 12 & 1 & 85 & $1: 0$ \\
\hline $12^{\mathrm{a}}$ & 5 & 1 & 13 & 5 & 62 & $5: 1$ \\
\hline $13^{\mathrm{b}}$ & 5 & 1 & 13 & 1 & 92 & $3: 1$ \\
\hline $14^{\mathrm{b}}$ & 5 & 1 & 13 & 0.5 & 93 & $4: 1$ \\
\hline $15^{\mathrm{a}}$ & 5 & 2 & 14 & 5 & 71 & $6: 1$ \\
\hline $16^{\mathrm{b}}$ & 5 & 2 & 14 & 1 & 62 & $6.5: 1$ \\
\hline $17^{\mathrm{b}}$ & 5 & 2 & 14 & 0.5 & 65 & $6.5: 1$ \\
\hline $18^{\mathrm{a}}$ & 5 & 3 & 15 & 5 & 56 & $15: 1$ \\
\hline $19^{\mathrm{b}}$ & 5 & 3 & 15 & 1 & 60 & $9: 1$ \\
\hline $20^{\mathrm{b}}$ & 5 & 3 & 15 & 0.5 & 57 & $19: 1$ \\
\hline
\end{tabular}

${ }^{\text {a }}$ Batch.

b Flow.

c Isolated yield.

${ }^{\mathrm{d}}$ Determined by ${ }^{1} \mathrm{H}$ NMR spectroscopy.

${ }^{\mathrm{e}}$ Reaction performed at $0{ }^{\circ} \mathrm{C}$.

${ }^{\mathrm{f}}$ Reaction performed at $-20{ }^{\circ} \mathrm{C}$.

g Microchannels occlusion.

fluidic conditions allow the reactions to proceed very fast. Undesirable side reactions, such as donor degradation, take place with residence times longer than one minute and may become more and more important and competitive. This was also confirmed by the higher purity of the reaction products when the glycosylations were performed at one minute of residence time.

In the next stage of our investigation we studied the behavior of thioglycosyl donors in microreactor. It should be emphasized that, to the best of our knowledge, the use of thioglycoside donors in glycosylations under continuousflow conditions has been little explored ${ }^{15}$ in comparison with trichloroacetimidates.

The flow reactions were carried out by pumping in the microreactor a solution containing the donor, the acceptor 
and NIS, while a $0.01 \mathrm{M}$ solution of TMSOTf was injected in the second inlet with a flow rate corresponding to one minute reaction time. In this way, the activation of the glycosyl donor by $\mathrm{I}^{+}$takes place in the microreactor soon after mixing the two solutions. Gratifyingly, glycosylations with thioglycosides 6-9 occurred smoothly at room temperature under microfluidic conditions, furnishing chemical yields and stereoselectivities mostly comparable to batch reactions even if performed using reagent grade dichloromethane (Scheme 3 and Table 2).

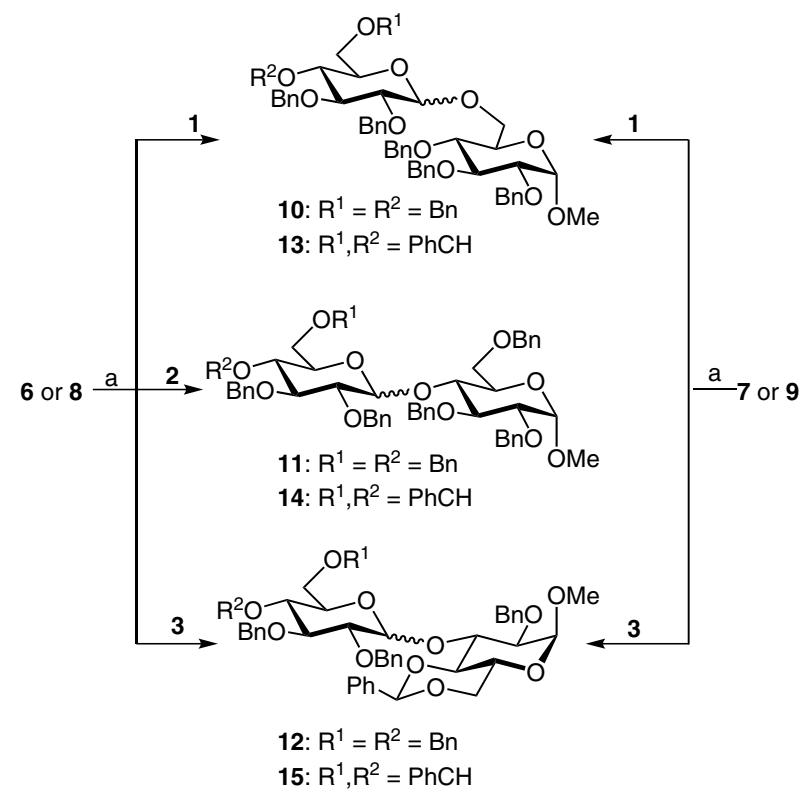

Scheme 3 Reagents and conditions: (a) NIS, TMSOTf (0.01 M), $\mathrm{CH}_{2} \mathrm{Cl}_{2}$.

In particular, while flow glycosylations of acceptors 1 and 2 provided from good to high yields of the corresponding disaccharides (Table 2, entries 2, 4, 8, 10, 14, and 18), acceptor 3 afforded significantly lower yields ( $10-15 \%$ less) of disaccharides $\mathbf{1 2}$ and $\mathbf{1 5}$ than batch reactions (Table 2, compare entries 5, 6, 11,12,15, 16, and 19,20).

To ensure that the efficiency of the microfluidic glycosylations is reproducible on a larger scale, we performed a laboratory scale-up using the glycosylation of acceptor $\mathbf{1}$ with donor $\mathbf{4}$ as a model reaction. According to the general procedure $C$ (see the experimental section in the Supporting Information file), solution A and solution $\mathrm{B}(5 \mathrm{~mL}$ each) were injected into a $100 \mu \mathrm{L}$ microreactor (purchased by Future Chemistry ${ }^{\circledR}$ ) setting the residence time to one minute. The glycosylation occurred smoothly and provided $0.44 \mathrm{~g}$ of disaccharide $\mathbf{1 0}$ over a total time of $100 \mathrm{~min}-$ utes $(90 \%$ isolated yield), corresponding to a production rate of $0.26 \mathrm{~g} / \mathrm{h}$.

These data show that both stereoselectivity and chemical yields of the microfluidic glycosylations do not basically differ from batch reactions. There are, however, significant practical advantages in microfluidic glycosylations, especially in view of an industrial implementation of the process. Optimized continuous-flow glycosylations af-
Table 2 Glycosylations Performed with Thioglycosyl Donors 6-9

\begin{tabular}{|c|c|c|c|c|c|c|}
\hline Entry & Donor & Acceptor & Product & $\begin{array}{l}\text { Time } \\
(\mathrm{min})\end{array}$ & $\begin{array}{l}\text { Yield } \\
(\%)^{c}\end{array}$ & $\alpha / \beta^{\mathrm{d}}$ \\
\hline $1^{\mathrm{a}}$ & 6 & 1 & 10 & 5 & 71 & $1: 1$ \\
\hline $2^{b}$ & 6 & 1 & 10 & 1 & 81 & $1.4: 1$ \\
\hline $3^{\mathrm{a}}$ & 6 & 2 & 11 & 5 & 69 & $2: 1$ \\
\hline $4^{b}$ & 6 & 2 & 11 & 1 & 67 & $1.8: 1$ \\
\hline $5^{\mathrm{a}}$ & 6 & 3 & 12 & 5 & 90 & $3.5: 1$ \\
\hline $6^{\mathrm{b}}$ & 6 & 3 & 12 & 1 & 76 & $5: 1$ \\
\hline $7^{\mathrm{a}}$ & 8 & 1 & 13 & 5 & 80 & $4.5: 1$ \\
\hline $8^{b}$ & 8 & 1 & 13 & 1 & 70 & $3.4: 1$ \\
\hline $9^{\mathrm{a}}$ & 8 & 2 & 14 & 5 & 55 & $4.5: 1$ \\
\hline $10^{\mathrm{b}}$ & 8 & 2 & 14 & 1 & 56 & $4.4: 1$ \\
\hline $11^{\mathrm{a}}$ & 8 & 3 & 15 & 5 & 88 & $2.6: 1$ \\
\hline $12^{\mathrm{b}}$ & 8 & 3 & 15 & 1 & 60 & $3: 1$ \\
\hline $13^{\mathrm{a}}$ & 7 & 1 & 10 & 5 & 68 & $1.6: 1$ \\
\hline $14^{\mathrm{b}}$ & 7 & 1 & 10 & 1 & 81 & $1.5: 1$ \\
\hline $15^{\mathrm{a}}$ & 7 & 3 & 12 & 5 & 86 & $3.9: 1$ \\
\hline $16^{\mathrm{b}}$ & 7 & 3 & 12 & 1 & 69 & $5: 1$ \\
\hline $17^{\mathrm{a}}$ & 9 & 1 & 13 & 5 & 65 & $4: 1$ \\
\hline $18^{\mathrm{b}}$ & 9 & 1 & 13 & 1 & 80 & $4: 1$ \\
\hline $19^{\mathrm{a}}$ & 9 & 3 & 15 & 5 & 88 & $2.9: 1$ \\
\hline $20^{\mathrm{b}}$ & 9 & 3 & 15 & 1 & 75 & $4.8: 1$ \\
\hline
\end{tabular}

${ }^{\mathrm{a}}$ Batch.

${ }^{\mathrm{b}}$ Flow.

${ }^{\mathrm{c}}$ Isolated yield.

${ }^{\mathrm{d}}$ Determined by ${ }^{1} \mathrm{H}$ NMR spectroscopy.

ford satisfying chemical yields with all glycosyl donors tested and offer the unquestionable benefit of using reagent-grade solvents at room temperature, with no need to remove moisture from the reaction mixture and to use an expensive inert atmosphere.

As mentioned above, the application of flow chemistry to multistep synthesis has been widely reported and documented either in combination with immobilized reagents, scavengers, and catch-and-release protocols, ${ }^{16}$ or even in a continuous-flow process through multiple microreactors without additional components. ${ }^{17,9}$ However, to the best of our knowledge, there are no examples of one-flow multistep synthesis of oligosaccharides that would be a crucial issue to convincingly establish the microfluidic devices as valuable tools to speed up and expand the industrial development of saccharide-based drugs. Taking advantage of the distinctive mode of activation of trichloroacetimidates and thioglycosides, we anticipated that two consecutive glycosylations could be combined in a single procedure 
and carried out in two interconnected microreactors, with no need of intermediate quenching. The experiment was designed and accomplished as follows (Scheme 4). A dichloromethane solution of 2-O-acetyl-3,4,6-tri-O-benzyl$\alpha$-D-glucopyranosyl trichloroacetimidate $(\mathbf{1 6})^{18}$ and acceptor $\mathbf{1 7}$ - obtained from thioglycoside 9 by reductive opening of the benzylidene acetal - and a $0.02 \mathrm{M}$ dichloromethane solution of TMSOTf were pumped in the first microreactor, setting the reaction time at two minutes. The glycosylation occurred, then the solution containing the disaccharide thioglycoside $\mathbf{1 8}$ and TMSOTf flowed from the outlet of the microreactor and was directly conveyed to the inlet of the second microreactor, together with a dichloromethane solution of acceptor $\mathbf{1}$ and NIS. Eventually, the newly formed trisaccharide 19 was recovered at the outlet of the second microreactor after neutralization of TMSOTf with triethylamine. Chromatographic purification provided trisaccharide 19 in 51\% overall yield. NMR analysis showed the exclusive formation of a $\beta$-glycosidic bond in the first glycosylation, leading to disaccharide donor 18, while the subsequent coupling afforded a mixture of anomers (estimated as $6.3: 1 \alpha / \beta$ ratio by NMR spectroscopy) at the second glycosidic linkage of trisaccharide 19. The multistep synthesis of trisaccharide 19 and full characterization data of compounds 18 and 19 are reported in the Supporting Information.

We performed a systematic study to explore the application of microreactors technology in oligosaccharide synthesis. Two of the most widespread glycosyl donors, trichloroacetimidates and thioglycosides, were coupled with different glycosyl acceptors under batch and microfluidic conditions. We found that, in comparison with traditional batch reactions, the glycosylations carried out under continuous-flow conditions occur with very similar stereoselectivity and comparable or even higher chemical yield. However, microfluidic glycosylations have some practical advantages, such as the possibility to be performed in standard-grade solvent at room temperature. Also thioglycosides, which are notoriously highly sensitive to traces of moisture in the reaction mixture, afforded the corresponding disaccharides with high efficiency.

Further benefits of microreactors derive from their use for the multistep synthesis. Multistep flow reactions can indeed accelerate the development of efficient chemical processes for the discovery and production of saccharidebased lead compounds, enabling a drastic reduction of manufacturing costs. As a proof of concept, we synthesized a trisaccharide performing two consecutive glycosylations into interconnected microreactors. The large variety of glycosyl donors that can be activated in such a highly specific manner enables to design the multistep synthesis of even complex oligosaccharides profiting by the technical ease and flexibility of microreactors.

All these characteristics feature the very promising microreactors technology, but additional investigations are definitely required to explore drawbacks and potential of microfluidic devices. The study of the solvent effect, for example, performing the glycosylations in acetonitrile or diethyl ether, ${ }^{6 \mathrm{i}, \mathrm{j}, 19}$ could unveil significant insights on the application of this technique to oligosaccharide synthesis, and further efforts in this direction are currently underway in our laboratory.

\section{Acknowledgement}

We gratefully acknowledge MIUR-Italy (PRIN 2010-2011, contract 010JMAZML 003) for financial support.

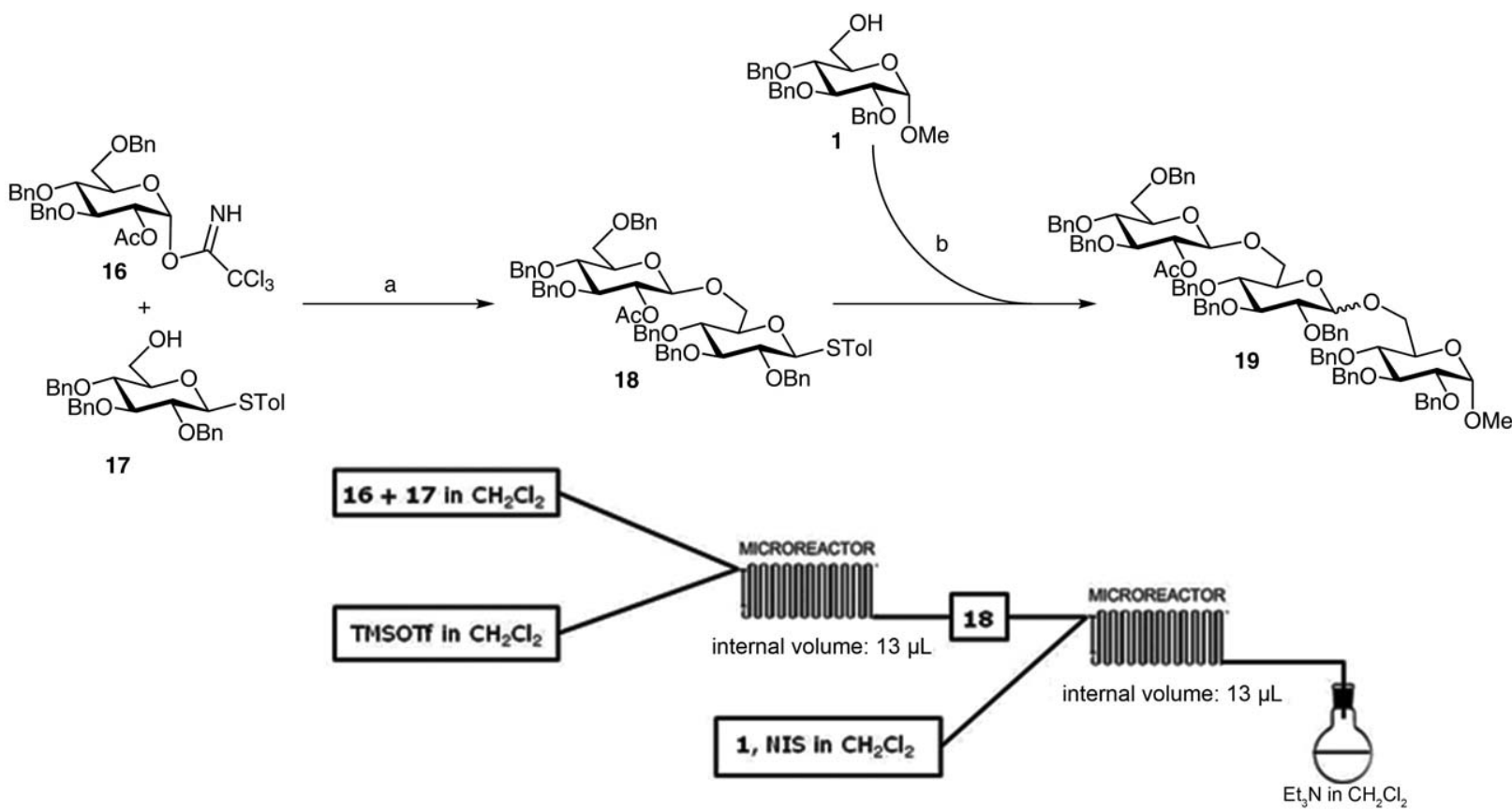

Scheme 4 Reagents and conditions: (a) TMSOTf (0.02 M), $\mathrm{CH}_{2} \mathrm{Cl}_{2}$; (b) 1 (0.05 M), NIS, $\mathrm{CH}_{2} \mathrm{Cl}_{2}$. 
Supporting Information for this article is available online at http://www.thieme-connect.com/products/ejournals/journal/ $10.1055 / \mathrm{s}-00000083$

\section{References and Notes}

(1) (a) Varki, A. Glycobiology 1993, 3, 97. (b) Dwek, R. A. Chem. Rev. 1996, 96, 683.

(2) (a) Sharon, N. Biochim. Biophys. Acta 2006, 1760, 527. (b) Balzarini, J. Nat. Rev. Microbiol. 2007, 5, 583. (c) Ernst, B.; Magnani, J. L. Nat. Rev. Drug Discovery 2009, 8, 661.

(3) Sofia, M. J. Med. Chem. Res. 1998, 8, 362.

(4) (a) Toshima, K.; Tatsuta, K. Chem. Rev. 1993, 93, 1503. (b) Nukada, T.; Berces, A.; Zgierski, M. Z.; Whitfield, D. M. J. Am. Chem. Soc. 1998, 120, 13291. (c) Boltje, T. J.; Buskas, T.; Boons, G.-J. Nat. Chem. 2009, 1, 611. (d) Galonić, D. P.; Gin, D. Y. Nature (London, U.K.) 2007, 446, 1000. (e) Lepenies, B.; Yin, J.; Seeberger, P. H. Curr. Opin. Chem. Biol. 2010, 14, 404. (f) Mydock, L. K.; Demchenko, A. V. Org. Biomol. Chem. 2010, 8, 497.

(5) (a) Pennemann, H.; Watts, P.; Haswell, S. J.; Hessel, V.; Löwe, H. Org. Process Res. Dev. 2004, 8, 422. (b) Watts, P. Curr. Opin. Drug Discovery Dev. 2004, 7, 807. (c) Dittrich, P. S.; Manz, A. Nat. Rev. Drug Discovery 2006, 5, 210. (d) Wheeler, R. C.; Benali, O.; Deal, M.; Farrant, E.; MacDonald, S. J. F.; Warrington, B. H. Org. Process Res. Dev. 2007, 11, 704. (e) Mason, B. P.; Price, K. E.; Steinbacher, J. L.; Bogdan, A. R.; McQuade, D. T. Chem. Rev. 2007, 107, 2300. (f) Sahoo, H. R.; Kralj, J. G.; Jensen, K. F. Angew. Chem. Int. Ed. 2007, 46, 5704. (g) Geyer, K.; Gustafsson, T.; Seeberger, P. H. Synlett 2009, 2382. (h) Noël, T.; Buchwald, S. L. Chem. Soc. Rev. 2011, 40, 5010. (i) Anderson, N. G. Org. Process Res. Dev. 2012, 16, 852. (j) Hartman, R. L.; McMullen, J. P.; Jensen, K. F. Angew. Chem. Int. Ed. 2011, 50, 7502.

(6) (a) Ratner, D. M.; Murphy, E. R.; Jhunjhunwala, M.; Snyder, D. A.; Jensen, K. F.; Seeberger, P. H. Chem. Commun. 2005, 578. (b) Geyer, K.; Codée, J. D. C.; Seeberger, P. H. Chem. Eur. J. 2006, 12, 8434. (c) Geyer, K.; Seeberger, P. H. Helv. Chim. Acta 2007, 90, 395. (d) Carrel, F. R.; Geyer, K.; Codée, J. D. C.; Seeberger, P. H. Org. Lett. 2007, 9, 2285. (e) Fukase, K.; Takashina, M.; Hori, Y.; Tanaka, D.; Tanaka, K.; Kusumoto, S. Synlett 2005, 2342. (f) Tanaka, K.; Mori, Y.; Fukase, K. J. Carbohydr. Chem. 2009, 28, 1. (g) Tanaka, K.; Miyagawa, T.; Fukase, K. Synlett 2009, 1571. (h) Tanaka, K.; Fukase, K. Beilstein J. Org. Chem. 2009, 5, 40. (i) Tanaka, K.; Fujii, Y.; Tokimoto, H.; Mori, Y.; Tanaka, S. I.; Bao, G.; Siwu, E. R. O.; Nakayabu, A.; Fukase, K. Chem. Asian J. 2009, 4, 574. (j) Tanaka, K.; Fukase, K. Org. Process Res. Dev. 2009, 13, 983 .

(7) Oberbillig, T.; Löwe, H.; Hoffmann-Röder, A. J. Flow Chem. 2012, 2, 83.

(8) Wojcik, F.; O’Brien, A. G.; Götze, S.; Seeberger, P. H.; Hartmann, L. Chem. Eur. J. 2013, 19, 3090.
(9) (a) Webb, D.; Jamison, T. F. Chem. Sci. 2010, 1, 675. (b) McQuade, D. T.; Seeberger, P. H. J. Org. Chem. 2013, 78, 6384; and references cited therein.

(10) (a) Sniady, A.; Bedore, M. W.; Jamison, T. F. Angew. Chem. Int. Ed. 2011, 50, 2155. (b) Shen, B.; Jamison, T. F. Org. Lett. 2012, 14, 3348.

(11) This work is a major part of the $\mathrm{PhD}$ thesis of Damiano Cancogni (2014).

(12) (a) Boonyarattanakalin, S.; Liu, X.; Michieletti, M.; Lepenies, B.; Seeberger, P. H. J. Am. Chem. Soc. 2008, 130, 19791. (b) Kalikanda, J.; Li, Z. Carbohydr. Res. 2011, 346, 2380. (c) Gangadharmath, U. B.; Demchenko, A. D. Synlett 2004, 2191.

(13) (a) Gaikwad, N. W.; Hwang, G. S.; Goldberg, I. H. Org. Lett. 2004, 6, 4833. (b) Izumi, M.; Fukase, K.; Kusumoto, S. Biosci. Biotechnol. Biochem. 2002, 66, 211. (c) Qiao, L.; Vederas, J. C. J. Org. Chem. 1993, 58, 3480. (d) Koch, S.; Schollmeyer, D.; Löwe, H.; Kunz, H. Chem. Eur. J. 2013, 19, 7020

(14) (a) Zhang, F.; Zhang, W.; Curran, D. P.; Liu, G. J. Org. Chem. 2009, 74, 2594. (b) France, R. R.; Compton, R. G.; Davis, B. G.; Fairbanks, A. J.; Rees, N. V.; Wadhawan, J. D. Org. Biomol. Chem. 2004, 2, 2195. (c) Lu, L. D.; Shie, C. R.; Kulkarni, S. S.; Pan, G. R.; Lu, X. A.; Hung, S. C. Org. Lett. 2006, 8, 5995.

(15) Saito, K.; Ueoka, K.; Matsumoto, K.; Suga, S.; Nokami, T.; Yoshida, J. Angew. Chem. Int. Ed. 2011, 50, 5153.

(16) (a) Ley, S. V.; Baxendale, I. R.; Bream, R. N.; Jackson, P. S.; Leach, A. G.; Longbottom, D. A.; Nesi, M.; Scott, J. S.; Storer, I. R.; Taylor, S. J. J. Chem. Soc., Perkin Trans. 1 2000, 3815. (b) Baxendale, I. R.; Deeley, J.; Griffiths-Jones, C. M.; Ley, S. V.; Saaby, S.; Tranmer, G. K. Chem. Commun. 2006, 2566. (c) Baxendale, I. R.; Ley, S. V.; Mansfield, A. C.; Smith, C. D. Angew. Chem. Int. Ed. 2009, 48, 4017. (d) Baxendale, I. R.; Schou, S. C.; Sedelmeier, J.; Ley, S. V. Chem. Eur. J. 2010, 16, 89. (e) Martin, L. J.; Marzinzik, A. L.; Ley, S. V.; Baxendale, I. R. Org. Lett. 2011, 13, 320. (f) Smith, C. J.; Smith, C. D.; Nikbin, N.; Ley, S. V.; Baxendale, I. R. Org. Biomol. Chem. 2011, 9, 1927. (g) Smith, C. J.; Nikbin, N.; Ley, S. V.; Lange, H.; Baxendale, I. R. Org. Biomol. Chem. 2011, 9, 1938. (h) Pastre, J. C.; Browne, D. L.; Ley, S. V. Chem. Soc. Rev. 2013, 42, 8849; and references cited therein.

(17) (a) Bogdan, A. R.; Poe, S. L.; Kubis, D. C.; Broadwater, S. J.; McQuade, D. T. Angew. Chem. Int. Ed. 2009, 48, 8547. (b) Stazi, F.; Cancogni, D.; Turco, L.; Westerduin, P.; Bacchi, S. Tetrahedron Lett. 2010, 51, 5385. (c) Kopetzki, D.; Lévesque, F.; Seeberger, P. H. Chem. Eur. J. 2013, 19, 5450 .

(18) (a) Tiwari, V. K.; Kumar, A.; Schmidt, R. R. Eur. J. Org. Chem. 2012, 15, 2945. (b) Schmidt, R. R.; Effenberger, G. Carbohydr. Res. 1987, 171, 59. (c) Zhang, Z.; Zong, C.; Song, G.; Lv, G.; Chun, Y.; Wang, P.; Ding, N.; Li, Y. Carbohydr. Res. 2010, 345, 750.

(19) Tanaka, S. I.; Goi, T.; Tanaka, K.; Fukase, K. J. Carbohydr. Chem. 2007, 26, 369. 